\title{
STATUS REPORT ON THE TERRASAR-X MISSION
}

\author{
S. Buckreuss ${ }^{1}$, A. Roth ${ }^{2}$ \\ ${ }^{1}$ Microwaves and Radar Institute \\ ${ }^{2}$ German Remote Sensing Data Center (DFD) \\ German Aerospace Center (DLR) - Oberpfaffenhofen \\ D-82234 Wessling \\ Email: stefan.buckreuss@dlr.de
}

\begin{abstract}
TerraSAR-X is Germany's first national remote sensing satellite being implemented in a public-private partner-ship between the German Aerospace Centre (DLR) and EADS Astrium GmbH. TerraSAR-X was launched on June 15th, 2007 and will supply high-quality radar data for purposes of scientific observation of the Earth for a period of at least five years. At the same time it is designed to satisfy the steadily growing demand of the private sector for remote sensing data in the commercial market [1].
\end{abstract}

Index Terms - TerraSAR-X, radar, satellite, launch and early orbit phase, commissioning phase, system potential

\section{INTRODUCTION}

The TerraSAR-X features an advanced high-resolution XBand Synthetic Aperture Radar based on the active phased array technology which allows the operation in Spotlight-, Stripmap- and ScanSAR Mode with various polarizations. It combines the ability to acquire high resolution images for detailed analysis as well as wide swath images for overview applications. In addition, experimental modes like the Dual Receive Antenna Mode allow for full-polarimetric imaging as well as along track interferometry, i.e. moving target identification

\section{THE TERRASAR-X SATELLITE}

The TerraSAR-X satellite bus is a heritage from the successful Champ and Grace missions. The TerraSAR-X features an advanced high-resolution X-Band (9.65 GHz) Synthetic Aperture Radar based on the active phased array technology which allows the operation in Spotlight-, Stripmap- and ScanSAR mode with two polarizations in various combinations. It combines the ability to acquire high resolution images for detailed analysis as well as wide swath images for overview applications. The resolution varies from $1 \mathrm{~m}$ to $3.5 \mathrm{~m}$ for Spotlight-, $3 \mathrm{~m}$ for Stripmap- and $16 \mathrm{~m}$ for Scan SAR-mode. Were the swath width ranges from $30 \mathrm{~km}$ (Stripmap) to $100 \mathrm{~km}$ (ScanSAR). The size of the spotlight szenes is $10 \mathrm{~km} \times 5 \mathrm{~km}$ to $10 \mathrm{~km}$ (range $\times$ azimuth) [2].

\section{THE TERRASAR-X GROUND SEGMENT}

The TerraSAR-X Ground Segment is provided by DLR and constitutes the central element for controlling and operating the TerraSAR-X satellite, for calibrating its SAR instrument, and for archiving the SAR data as well as generating and distributing the basic data products [3].

The DLR Ground Segment is based on existing national infrastructure as much as possible and will be optimized for flexible response to (scientific and commercial) user requests and fast image product turn-around times. It is composed of three major elements:

- The Mission Operations Segment (MOS) provided by the German Space Operation Center (GSOC).

- The Payload Ground Segment (PGS) provided by the German Remote Sensing Data Center (DFD) and the DLR Remote Sensing Technology Institute (IMF).

- The Instrument Operation and Calibration Segment (IOCS) provided by the Microwaves and Radar Institute (IHR).

\section{SCIENTIFIC COORDINATION AND COMMERCIAL EXPLOITATION}

TerraSAR-X is an operational SAR-system for scientific and commercial applications. The commercial exploitation is exclusively granted to Astrium / Infoterra GmbH.

DLR is responsible for the scientific utilization of the TerraSAR-X products. The status "scientific use" needs to be gained via a selection process. The Science Service System (http://sss.terrasar-x.dlr.de/) was developed for this purpose. Since end of October 2007 new proposals can be submitted at any time. The corresponding TerraSAR-X data will be provided to the costs of fulfilling the user request. 
Further Announcements of Opportunity (AOs) are planned where special conditions might be applied with respect to the data provision.

Commercial customers, on the other hand, will have to contact Infoterra (http://www.terrasar.com/) for access to TerraSAR-X data via the commercial TerraSAR-X Exploitation and Service Infrastructure (TSXX) developed by Infoterra. In addition to the baseline station in Neustrelitz, Infoterra will set up additional receiving stations for Direct Access Customers (DAC) respectively Direct Access Partners (DAP). These so called Direct Access Stations (DAS) are foreseen to extend the baseline receiving station concept.

\section{MISSION STATUS}

\subsection{Launch and Early Orbit Phase (LEOP)}

TerraSAR-X was successfully launched on June $15^{\text {th }}, 2007$, 2:14 UTC on a Dnepr-1 in Baikonour, Kasachstan. During the LEOP the basic functionalities of the bus and the prime and secondary payload were checked out successfully. The first image was processed at LEOP day 5 on June $19^{\text {th }}$, 2007. All standard imaging modes (strip, spot \& scan) have been exercised. Therefore The Launch and Early Orbit Phase was successfully completed on June $21^{\text {st }}$, 2007. All activities planned were performed as scheduled.

\subsection{Commissioning Phase Baseline Tasks}

\subsubsection{Orbit and Attitude Verification}

The orbit and attitude products were verified explicitly by using laser ranging. The attitude product verification is covered implicitly by the instrument pointing calibration. The manoeuvre planning based on the reference orbit concept ensures the satellite is kept within a $\pm 250 \mathrm{~m}$ orbit tube [5].

\subsubsection{Instrument Characterization/Verification}

Focal points of the investigations were instrument temperature characterization and check of instrument configurations for basic modes as well as special settings for antenna pattern and pointing calibration [6] [7].

\subsubsection{Overall SAR system performance characterization}

The overall SAR system performance characterization comprises an initial characterization during the first cycles over scenes with one corner reflector in order to verify the format of the quick look images, header and radar raw data. The correctness of the data take commanding was verified via raw data and point target analysis. The characterization was then extended to verify the consistency of imaged scenes with selected modes and beams via evaluation of the response of several corner reflectors [5][8].
5.2.4. Calibration of the radar data

The TerraSAR-X calibration comprises the

- geometric calibration,

- antenna pointing calibration,

- antenna model verification,

- relative radiometric calibration

- absolute radiometric calibration

- internal instrument calibration

To ensure the successful execution of the different calibration procedures, dedicated calibration campaigns were performed. A calibration field was established in the vicinity of Oberpfaffenhofen, Germany enclosing an area of $120 \mathrm{~km} \times 40 \mathrm{~km}$. Calibration targets like corner reflectors, transponders and ground receivers were deployed at 30 positions. At the end more than 80 calibration campaigns with deployed reference targets and about 90 acquisitions across the Amazon rainforest were carried out and more than 1000 data takes were evaluated [9][10].

5.2.5. Check-out of receiving station and processing system The check out of the reception and transcription systems and the SAR processing system was performed including all inputs, such as SAR and calibration raw data, SAR header data, orbit and attitude products, processor settings and auxiliary products comprising calibration data and instrument parameters.

5.2.6. SAR product verification and release of the basic products

The SAR product verification was performed comprising the archive product verification and the delivery product verification w.r.t. format, annotation and content.

5.2.7. Load tests including the commercial service segment Two dedicated load test campaigns were performed in order to simulate a realistic load for ordering, processing and delivery work flow [11]. A high number of requests as expected in the operational phase were generated including conflicting orders in order to test the mission planning system [12] and to detect hidden errors in the work flows. Furthermore a check out of Direct Access Stations operated by Infoterra $\mathrm{GmbH}$ was included in the test program.

\subsubsection{Interferometric processing}

The interferometric processing was based on the nominal L1b products only and was used in the SAR product verification context for complex data product format verification including binary annotation and for consistency checks with annotated processing parameters such as Doppler, timing, velocity "B" parameter, etc. Also the relative geolocation accuracy was assessed and the relative orbit accuracy was derived. The phase preserving processing and product formatting were verified [13] [14].

\subsubsection{Operational user interfaces}

The operational interfaces were opened in early August 2007 between the TerraSAR-X ground segment provided by 
DLR and the TerraSAR-X Exploitation Infrastructure (TSXX) which is provided by Infoterra GmbH. The future product ordering and catalogue product ordering was enabled. Thus the commercial service segment was betimes included in the testing program in order to ensure a smooth start of the commercial business.

\subsubsection{SAR product verification:}

The SAR product verification comprises the archive product verification and the delivery product verification. Amongst others the format, annotation and content are verified [15] [16]. After all the results of the commissioning phase are reflected in the updated basic product specification [17], including also improvements with respect to the initial version as for example the

- improvement in absolute radiometric accuracy from $1.1 \mathrm{~dB}$ to $0.6 \mathrm{~dB}$

- improvement in relative radiometric accuracy from $0.68 \mathrm{~dB}$ to $0.31 \mathrm{~dB}$

- improvement in spotlight mode (azimuth) resolution from $2.2 \mathrm{~m}$ to $1.7 \mathrm{~m}$

- improvement in pixel localization accuracy from 2.0 $\mathrm{m}$ to $0.3 \mathrm{~m}$ in range and $0.53 \mathrm{~m}$ in azimuth

- improvements in side lobe ratio of ca. $4 \mathrm{~dB}$. In order to improve the side lobe ratios the weighting function was adopted at the cost of an acceptable reduction of the slant range resolution of $9 \%$ from $1.1 \mathrm{~m}$ to $1.2 \mathrm{~m}$.

Finally the experimental high resolution spotlight (300 $\mathrm{MHz}$ ) products were characterized and the respective order option was activated.

\subsection{Investigating Further Potential of TerraSAR-X}

Alongside to the regular schedule the potential of the TerraSAR-X system comprising both space and ground segment was investigated with respect to the following applications:

- Repeat pass interferometry [18],

- Persistent scatterer potential [19],

- Along track interferometry utilizing the aperture switching mode for traffic measurements [20],

- TOPSAR mode which is a new acquisition mode proposed by E. Attema (ESA-ESTEC) and F. Rocca (POLIMI) [21]. This mode aims at achieving the same coverage and resolution as ScanSAR, but with a nearly uniform SNR and DTAR [22]. It is going to be the operational mode for Sentinel-1. Interferometric Wide Swath (IWS) mode. Meanwhile TOPSAR data takes were performed and a phase preserving processing and the TOPSAR interferometry was demonstrated [23].

- Effectiveness of the Total Zero Doppler Steering method to control the attitude of the satellite for a reduction of the Doppler offset. This method provides a minimal shift of the Doppler spectrum by the order of some $\mathrm{Hz}$ and thus eases the SAR processing [24].

- Suitability of the sensor for SAR oceanography, which benefits especially from the high special resolution of TerraSAR-X. New insights into measurements of wind fields, ocean waves and currents were made possible [25].

- Applicability for disaster management and crisis information: Flood mapping in Yorkshire, UK, July $3^{\text {rd }}, 2007$ and Villahermosa Mexico, November $6^{\text {th }}$, 2007, Oil Spill in Ukraine/Russia, Kerch Strait, November 2007, flooding in Myanmar, May 2008 and earthquake in China, May 2008 [26].

\section{CONCLUSION}

The commissioning phase [4] was finished right on schedule after 5.5 month and the goal was attained to ensure optimum SAR product quality and to accomplish the full operational readiness of the space and ground segment in December 2007. The TerraSAR-X team executed a very comprehensive program involving tasks such as calibration, characterization and verification of the SAR instrument and overall SAR system performance, and verification of the final image products. During the commissioning phase 12000 data takes were executed and all imaging modes were tested and verified. In several cases the obtained results even exceeded the initial specifications. Consequently TerraSAR-X turned out to be a very stable precision instrument for radar imaging.

Furthermore the potential of TerraSAR-X for repeat pass and along track interferometry and TOPSAR was shown. Novel techniques such as the Total Zero Doppler Steering proved their effectivity. The benefit from the high resolution provided by TerraSAR-X was demonstrated for geoscientific applications, oceanography and disaster monitoring.

On January $7^{\text {th }}$, 2008 the operational phase was kicked off and the image production for scientific and commercial users is running extremely satisfactory since then.

\section{REFERENCES}

[1] R. Werninghaus, S. Buckreuss, W. Pitz, TerraSAR-X Mission Status. In: IEEE International Geoscience and Remote Sensing Symposium (IGARSS), Barcelona, Spain, 2007

[2] S. Buckreuss, R. Werninghaus, W. Pitz, The German Satellite Mission TerraSAR-X. In: 2008 IEEE Radar Conference (RadarCon), Rome, Italy, 2008

[3] S. Buckreuss, P. Mühlbauer, J. Mittermayer, W. Balzer, R. Werninghaus, The TerraSAR-X Ground Segment. European Conference on Synthetic Aperture Radar (EUSAR), Dresden, Germany, 2006 
[4] J. Mittermayer, B. Schättler, M. Younis, TerraSAR-X Commissioning Phase Execution and Results. Accepted at: IEEE International Geoscience and Remote Sensing Symposium (IGARSS), Boston, USA, 2008.

[5] J. Mittermayer, M. Younis, B. Bräutigam, T. Fritz, R. Kahle, R. Metzig, Verification of TerraSAR-X System. IEEE Geoscience and Remote Sensing Symposium (IGARSS), Barcelona, Spain, 2007

[6] R. Metzig, B. Bräutigam, D. Polimeni, J. Böer, M. Bachmann, J. Mittermayer. TerraSAR-X Instrument Characterization / Verification. Accepted at: 7th European Conference on Synthetic Aperture Radar, Friedrichshafen, Germany, 2008.

[7] J. Mittermayer, U. Steinbrecher, A. Meta, N. Tous-Ramon, S. Wollstadt, M. Younis, J. Marquez, D. Schulze, C. Ortega, TerraSAR-X System Performance and Command Generation. Accepted at: 7th European Conference on Synthetic Aperture Radar, Friedrichshafen, Germany, 2008.

[8] J. Marquez-Martinez, C. Gonzalez, M. Younis, S. Wollstadt, R. Metzig, U. Steinbrecher, N. Tous-Ramon, A. Meta, J. Mittermayer, In-Orbit SAR Performance of TerraSAR-X. In: IEEE Geoscience and Remote Sensing Symposium (IGARSS), Barcelona, Spain, 2007

[9] M. Schwerdt, B. Bräutigam, M. Bachmann, B. Döring, TerraSAR-X Calibration - First Results. In: IEEE International Geoscience and Remote Sensing Symposium (IGARSS), Barcelona, Spain, 2007

[10] M. Schwerdt, B. Bräutigam, B. Döring, D. Schrank, J.H. Gonzalez, Final Results of the Efficient TerraSAR-X Calibration Method. Accepted at Radarcon 2008, Rome, Italy, 2008.

[11] E. Mikusch, M. Wolfmüller, E. Diedrich, D. Dietrich, M. Böttcher, Management of "Future Products" in the Distributed Payload Ground Segment for TerraSAR-X., Proceedings of DASIA 2003, Data Systems in Aerospace, Prague, ISBN 92-9092-842-5, 2003

[12] M. Wickler, A. Braun, M. Geyer, A Strategic Mission Planning Concept for TerraSAR-X. 8th International Symposium on Space Mission Operations and Ground Data Systems, Montreal, 2004.

[13] H. Breit, T. Fritz, B. Schättler, E. Börner, M. Lachaise, A. Niedermeier, M. Eineder, U. Balss, TerraSAR-X Payload Data Processing - First Experiences. In: IEEE International Geoscience and Remote Sensing Symposium (IGARSS), Barcelona, Spain, 2007

[14] B. Schättler, T. Fritz, H. Breit, N. Adam, U. Balss, M. Lachaise, M. Eineder, A. Niedermeier, TerraSAR-X SAR Data Processing from Commissioning and Early Orbit Phase. Accepted at: EARSeL Joint Workshop Remote Sensing: New Challenges of High Resolution, Bochum, Germany, 2008.

[15] T. Fritz, H. Breit, B. Schättler, U. Balss, M. Lachaise, M. Eineder, accepted at: TerraSAR- $X$ Image Products: Characterization and Verification, EUSAR 2008 Conference, Friedrichshafen, Germany, 2008.
[16] T. Fritz, H. Breit, B. Schättler, U. Balss, M. Lachaise, M. Eineder, TerraSAR-X Image Products: Characterization and Verification. Accepted at: 7th European Conference on Synthetic Aperture Radar, Friedrichshafen, Germany, 2008.

[17] TerraSAR-X Ground Segment, Basic Product Specification Document. TX-GS-DD-3302, Issue 1.5, February 2008.

[18] M. Eineder, N. Adam, R. Bamler, N. Yague-Martinez, H. Breit, TerraSAR-X Spotlight SAR Interferometry. Submitted to IEEE Transactions on Geoscience and Remote Sensing. 2008.

[19] N. Adam, M. Eineder, B. Schättler, N. Yague-Martinez, First TerraSAR-X Interferometry Evaluation. Fringe Workshop 2007 (ESA, Frascati)

[20] S. Suchandt, H. Runge, M. Eineder, H. Breit, A. Kotenkov, U. Balss, First Results of Ground Moving Target Analysis in TerraSAR-X Data. IEEE Geoscience and Remote Sensing Symposium (IGARSS), Barcelona, Spain, 2007.

[21] F.D. Zan, A.M. Guarnieri, TOPSAR: terrain observation by progressive scan. IEEE Trans. Geosci. Remote Sensing, vol. 44, no. 9, pp. 2352 -2360, Sept. 2006.

[22] A. Meta, J. Mittermayer, U. Steinbrecher, P. Prats, Investigations on the TOPSAR acquisition mode with TerraSARX. IEEE Geoscience and Remote Sensing Symposium (IGARSS), Barcelona, Spain, 2007.

[23] A. Meta, P. Prats, U. Steinbrecher, J. Mittermayer, R. Scheiber, TerraSAR-X TOPSAR and ScanSAR Comparison, accepted at: TerraSAR- $X$ Image Products: Characterization and Verification, EUSAR 2008 Conference, Friedrichshafen, Germany, 2008.

[24] H. Fiedler, E. Boerner, J. Mittermayer, G. Krieger, Total Zero Doppler Steering - A New Method for Minimizing the Doppler Centroid. In: IEEE Geoscience and Remote Sensing Letters, Vol. 2, Iss. 2, pp. 141 - 145, April 2005

[25] S. Lehner, J. Schulz-Stellenfleth, S. Brusch, TerraSAR-X Measurements of Wind Fields, Ocean Waves and Currents, SEASAR 2008, ESA, Frascati, Italy, 2008

[26] Center for Satellite Based Crisis Information. Available: http://www.zki.caf.dlr.de/ 